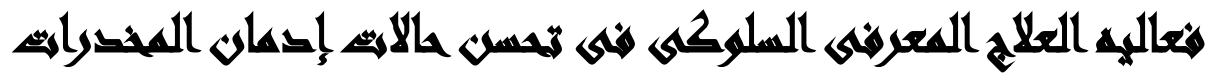 [iv]
}

\author{
أحمد مصطفى العتيق(')- أحمد فخرى هانى(')- رانيا حسن عبد الفتاح \\ ( ) معهد الدراسات والبحوث البيئية، جامعة عين شمس فمسنى
}

\section{المستخلئ}

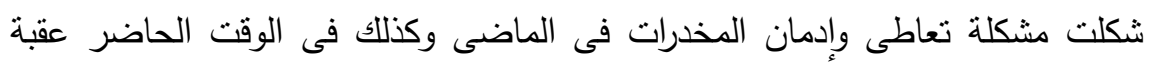

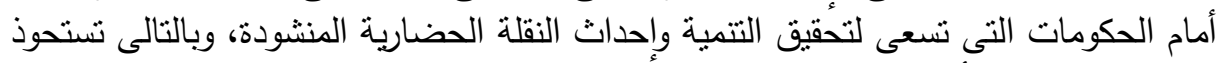

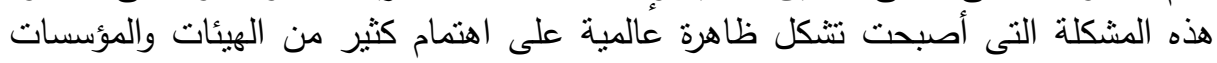

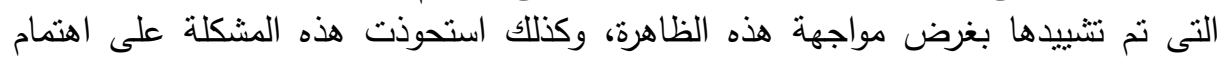

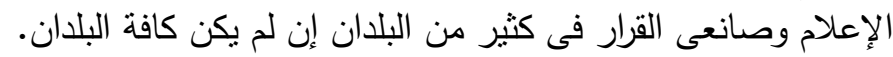

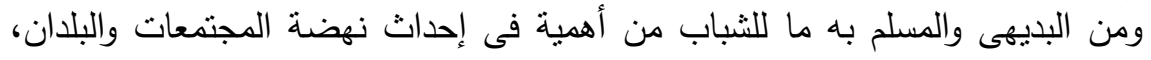

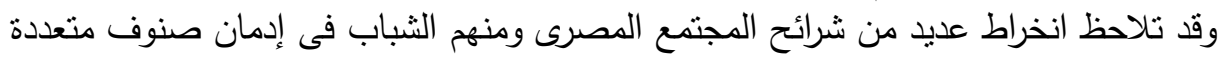

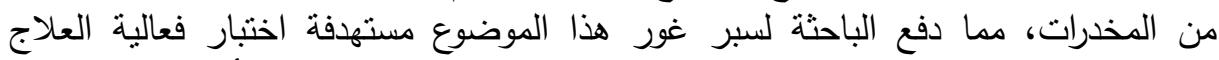

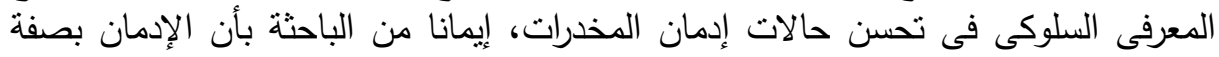
عامة نمط سلوكى غير سوى.

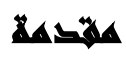

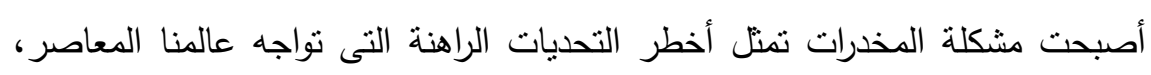

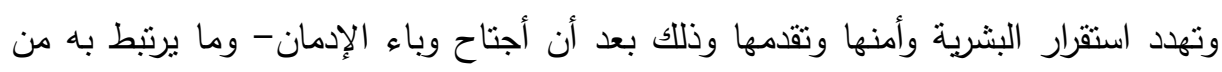

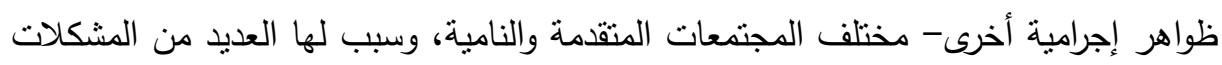

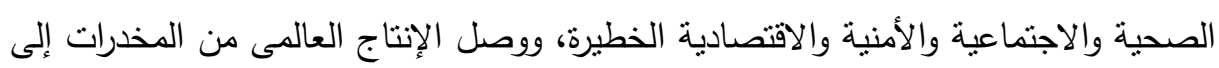

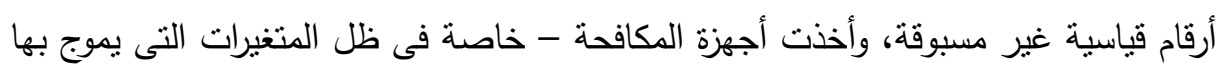

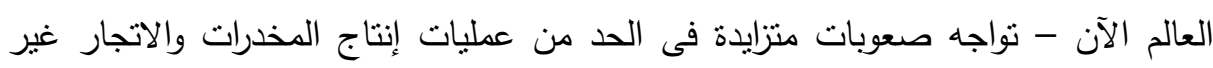

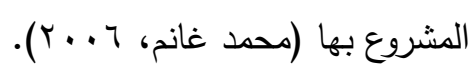

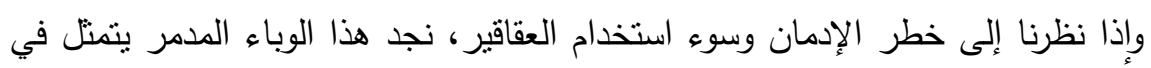

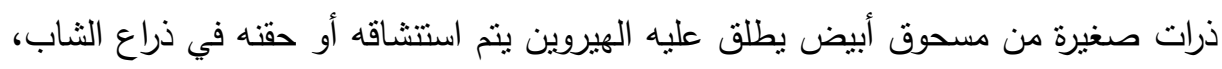

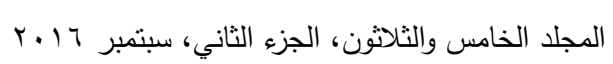


أو دخان مسموم يتصاعد من سيجارة أو غليون أو نرجيلة، أو حبة يبتلعها الثاب وهماً منه

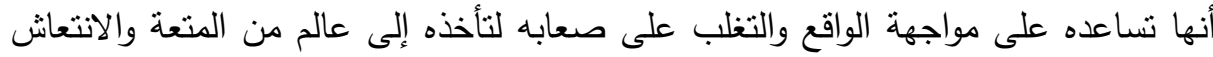

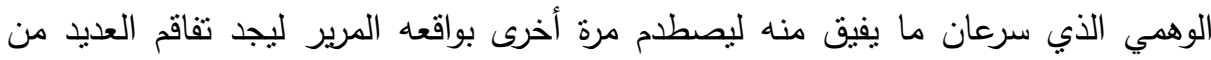

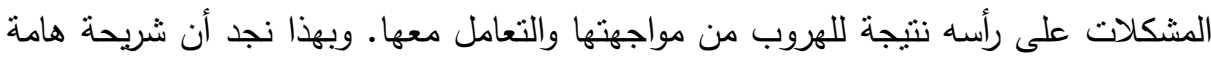
من شرائح المجتمع المتمنلة في شبابه ينحدرون إلى الهاوية آخذين معهم آمال وطموحات مات

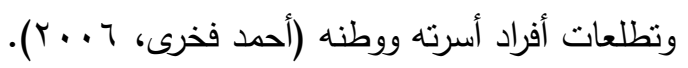

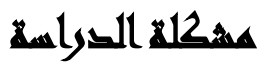

تعتبر مشكلة الإدمان مشكلة عالمية ذات جوانب متعددة ولا تختلف فى ذلك اية دولة

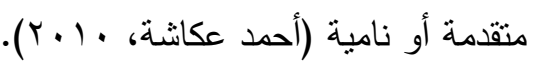

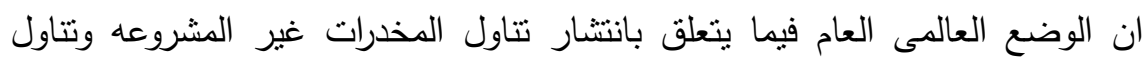
المخدرات الإثكالى (1) مستقر عموماً، وان التتاسب يتزايد بين العدد الإجمالى لمتتاولى لثاري المخدرات فى العالم كله ونمو سكان العالم. هذا وتتتشر فى كل منطقة مميزاتها الخاصة فيما يتعلق بكل مخدر معين، ولا يزال تتاول

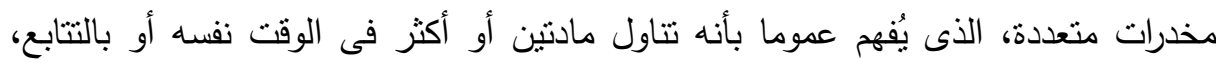
شاغلاً رئيسياً، سواء من منظور الصحة العامة أو من منظور هيئات مراقبة المخدرات.

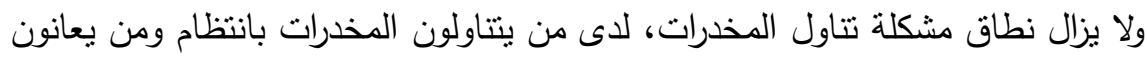

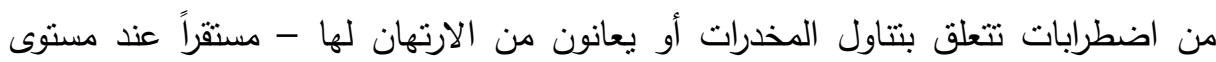

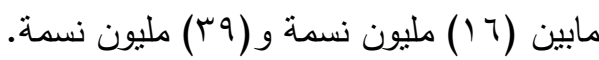

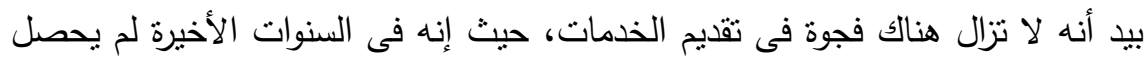

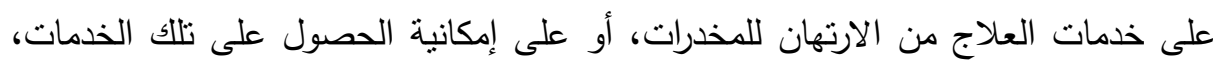
سوى واحد فقط من كل ستة من متتاولى المخدرات الإثكاليين فى العالم فى كل سنة (التقرير

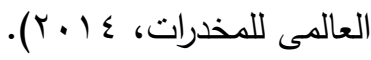
لا يوجد تعريف موحد لنتاول المخدرات الاثشكالي، فقد يختلف التعريف من بلد لآخر ، وقد يشمل من يستهلكون المخدرات على نحو شديد الخطورة، مثل من يتتاولون المخدرات بالحقن 
أو من يتتاولون المخدرات يوميا أو من نتخص حالاتهم بأنهم يعانون من اضطرابات تتعلق بتتاول المخدرات أو بأنهم مرتهنون للمخدرات. وتعتقد الباحثة أن هذه الأرقام ليست دقيقة لأن من المؤكد ان هناك حالات كثثرة غير

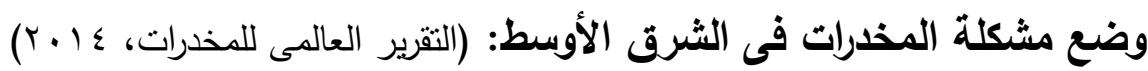
من خلال استبيان قام به المكتب الأقليمى بمنطقة الثرق الأوسط التابع لهنظمة الصحة الصنا

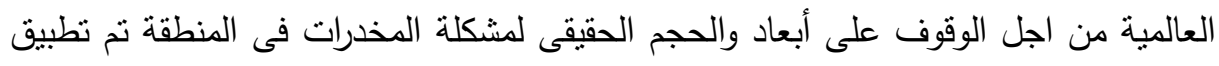
الاستبيان فى (9 (1) دولة هى (افغانستان- البحرين - جيبوتى - مصر - ايران - العراق -

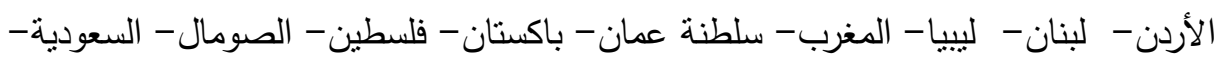
الإمارات العربية المتحدة- اليمن - السودان - سوريا).

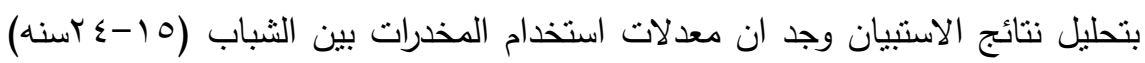

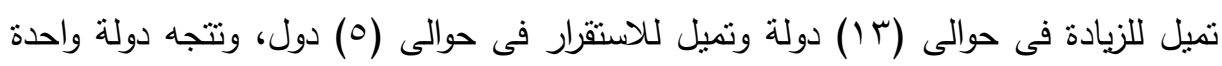
نحو الانخفاض، وكذلك بلغ منوسط العمر لبدء التعاطى من (10-1 (1) سنة تقريباً. وأوضح الدكتب الاقليمى المعنى بالمخدرات والجريمة فى الثرق الأوسط وشمال أفريقيا

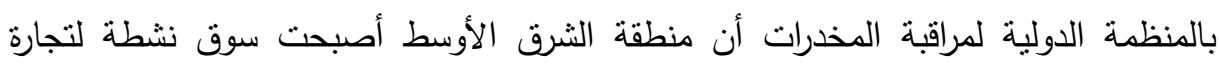

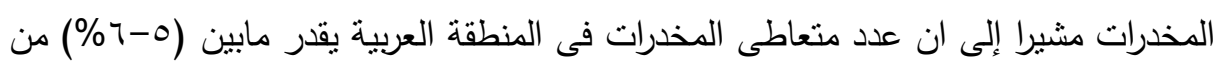
السكان.

وضع مشكلة المخدرات فى مصر: (المسح القومى، 11) تم رصد أهم واحدث

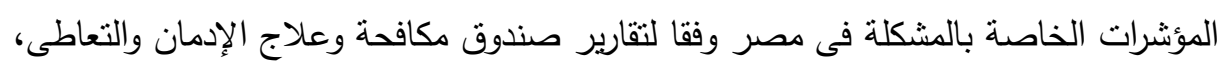
ووزارة الصحة والسكان، والإدارة العامة لمكافحة المخدرات. انخفاض ملحوظ فى سن التعاطى ليصل إلى مرحلتى الطفولة والمراهقة، حيث تدنى سن ولن النه بدء التعاطى إلى (11 عاماً) وبداية التخخين من (9 سنوات) بينما كان فى السابق يتراوح

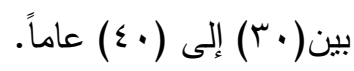


غياب الدور الحقيقى للوالدين فى مواجهه المشكلة، حيث إن(ه\%) من المدمنين يعيشون مع الوالدين، فى إنشارة واضحة لغياب دور الأسرة فى المواجهه.

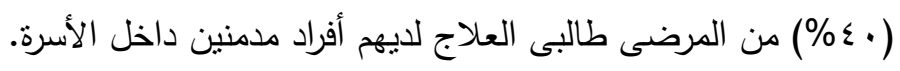

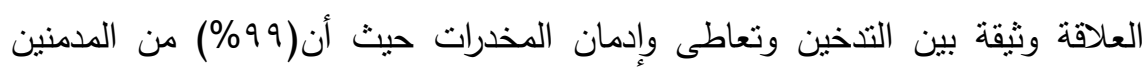

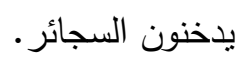

اضطراب الثخصية والانسياق وراء ضغط الأقران السلبى، والرغبة فى خوض التجربة

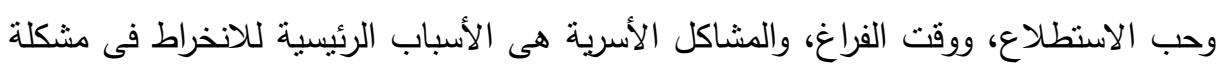

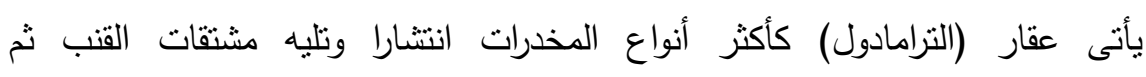
المورفينات، والمهدئات، والمنشطات، والجدير بالذكر أن تداول عقار (الترامادول) كمادة مخدرة

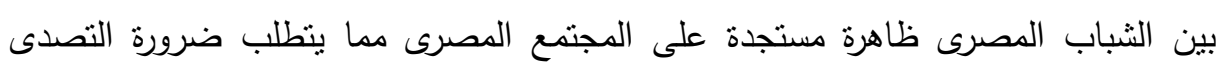
الحاسم لتداوله. وبناء على ذللك سوف تقوم الباحثه بإعداد برنامج للعلاج المعرفى السلوكى للمرضى فى محاوله لتقديم علاج متكامل يتضمن العلاج الدوائى والعلاج النفسى بأساليب متعددة (خاصنة

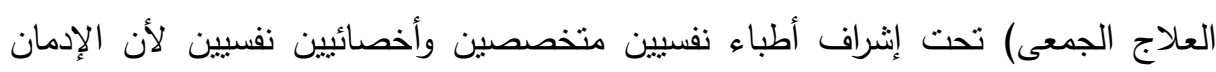

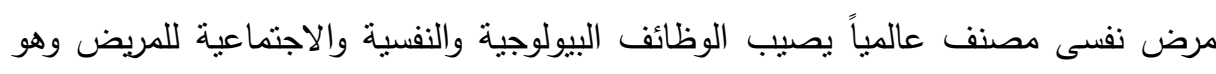

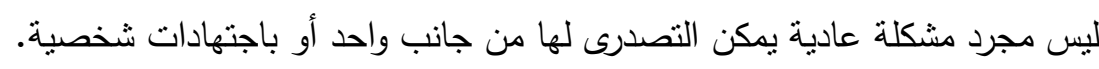

\section{أهمه التواسمة}

الأهمية النظرية: تعد هذه الدراسة محاولة علمية للتعرف على فعالية العلاج المعرفى السلوكى فى تحسن حالات إدمان المخدرات فالعلاج المعرفى السلوكى تستخدمه الباحثة كوسيلة لمساعدة الفرد فى تحليل خبراته بواقعية أكثر والتفكير بطريقة صحيحة ومعالجة

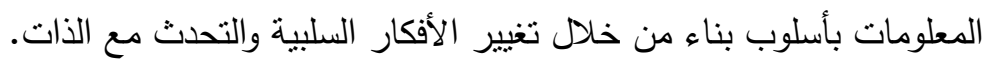


الأهمية التطبيقية: محاولة الاستفادة من نتائج هذه الدراسه فى اعداد برنامج علاجى

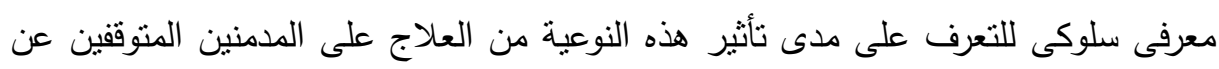
تعاطى المخدرات ومدى تحسنهم باختلاف شخصياتهم.

\section{أهمانهي التراسما}

تستهدف هذه الدراسة تحقيق هدف رئيس مؤداه "تحسين حالات إدمان المخدرات

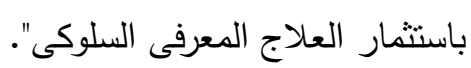

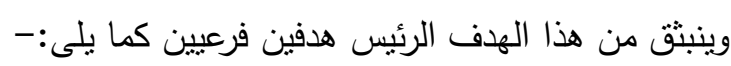

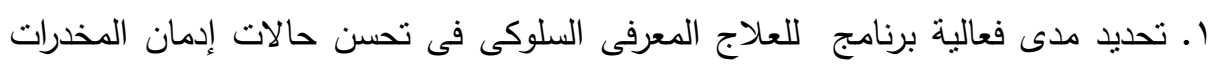
لأنماط منباينة من الثخصية. r. تحديد آليات العلاج المعرفى السلوكى فى تحسين حانه حالات إدمان المخدرات.

\section{هزوضر الفواسما}

تستهدف الدراسة الراهنة التحقق من صحة الفرضين التاليين:

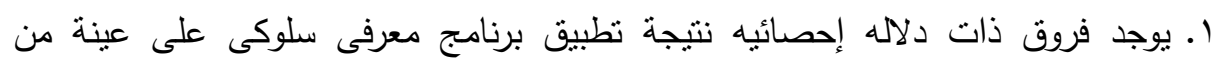

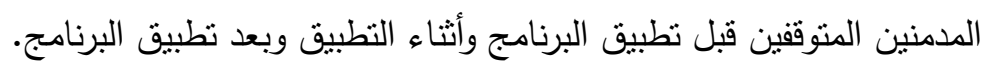

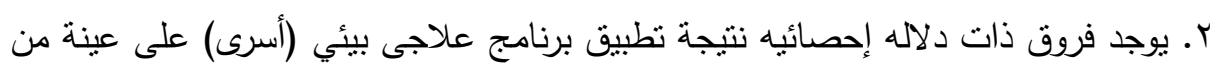
أسر المدمنين المتوقفين قبل تطبيق البرنامج وبعد التطبيق.

\section{مغاهميه التواسمة}

العلاج المعرفى السلوكى: يعرف العلاج المعرفى السلوكى بأنه "أحد الأساليب الحديثة فى

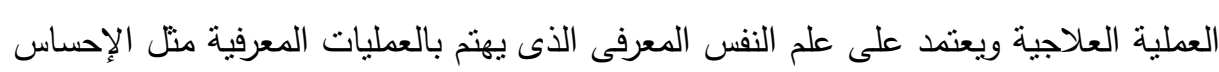

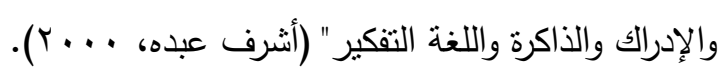

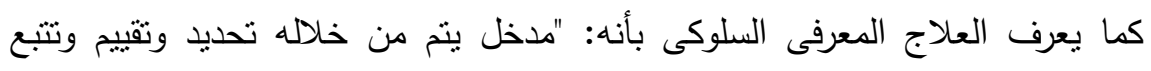

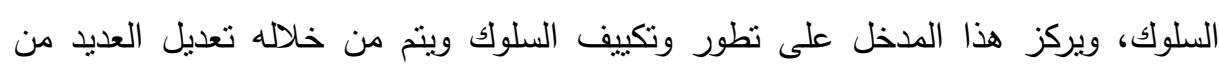

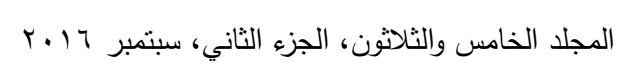


المشكلات منل: القلق، الاكتئاب، العدوان، وتعديل سلوكيات الأطفال والمراهقين والكبار، وهناك تداخل بين كلا من الأساس المعرفى والعلاج السلوكى وهما يعتمدان على العمليات

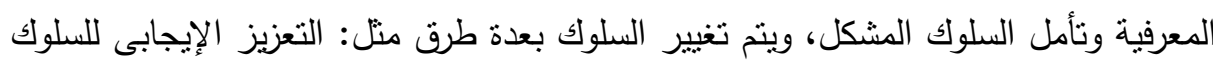

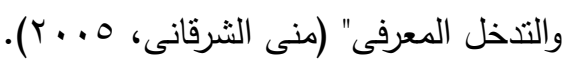
ويمكن للباحثة تقديم نعريف إجرائى للعلاج المعرفى السلوكى على النحو التالى:

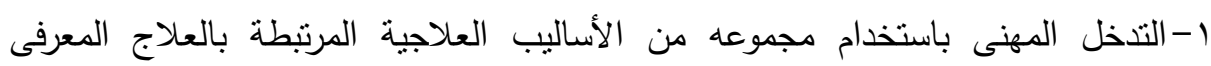
السلوكى. (- باك.

r-وذلك لتغيير الأفكار اللاعقلانية والمشاعر السلبية والسلوكيات غير المرغوبة المرتبطة

$$
\text { بمرض الإدمان. }
$$

r-ويتم ذلك من خلال برنامج علاجى به مجموعة من الأساليب:

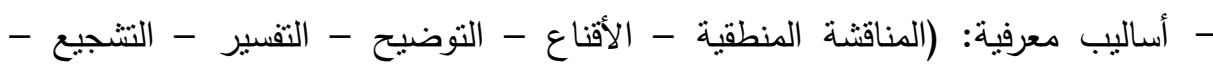

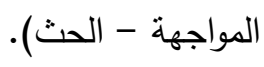

- أساليب انفعالية: (التأمل - ضبط الأنفعال - تعليم مهارات حل المشكلة - مهارة

$$
\text { الإسترخاء - مواجهة الانتكاسة - لعب الدور ). }
$$

- (ج) أساليب سلوكية: (التدعيم الإيجابى - النمذجة - الواجبات المنزلية - التقارير

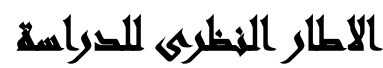

يتمركز المنطلق النظرى للاراسة فى المدخل المعرفى السلوكى: العلاج المعرفى السلوكى يمثل

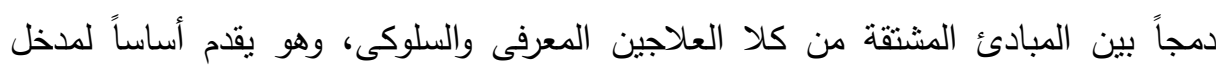

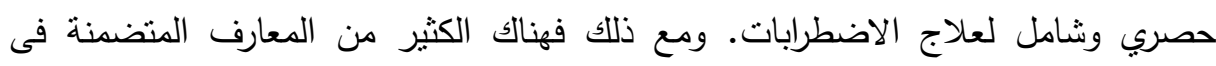
العلاج المعرفى السلوكى أكثر من تللك الموجودة فى النسخة القديمة من العلاج المعرفى.

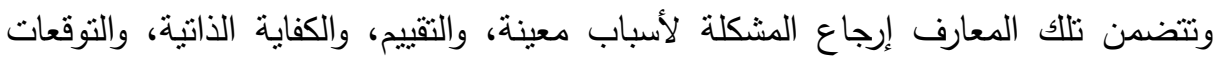
وغيرها. ... وهناك عناصر مشتركة فى العلاج المعرفي السلوكى وهى كما توضحها كريستين

(Kristen- 1999) 


$$
\text { • بركز المعالج على المشكلات الراهنة. }
$$

بضع أهدافا قابلة للتحقيق ومتفقا عليهاً مع العملاء.

• يسعى لتحقيق نتائج سريعة لمعظم المشكلات الملحة.

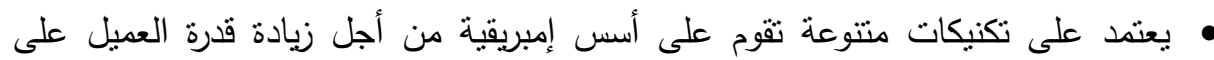

التعامل مع مشكلاته.

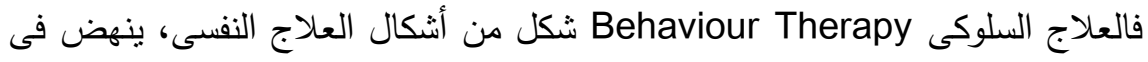
الأساس على المبادئ السلوكية، ويحاول المعالج فيه أن يغير الظروف المدعمة للسلوك غير المتكيف، ومع ذللك فقد اهتم المعالجون السلوكيون مؤخرا وبدرجة متزايدة بالأفكار والعمليات العقلية، وأصبح العلاج السلوكى يعد نوعا من العلاج المعرفى (جون سكوت، (1) ـ ب). والفرضية الرئيسة لهذا المدخل جوهرها "أن السلوك يتحدد من خلال ما يدركه الفرد وما يتكون لديه من عملية التعلم، فالسلوك قصد به تلك الاستجابات الظاهرة والتى يمكن ملاحظتها (التصرفات)، وكذلك الاستجابات غير الظاهرة منل الأفكار والانفعالات، فإذا تكون لدى الفرد

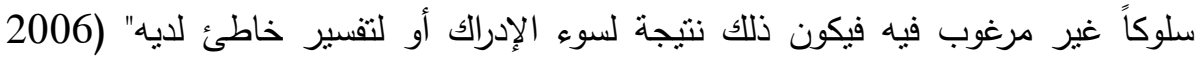

والعلاج المعرفى السلوكى هو تصنيف عام لأحد العلاجات النفسية وهناك العديد من

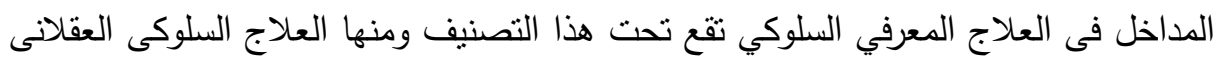
الانفعالى، والعلاج المعرفى، والعلاج السلوكى العقلانى، والعلاج الحياتى العقلانى، وعلاج

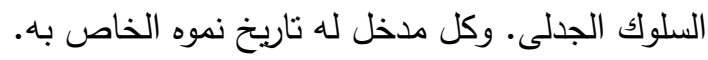

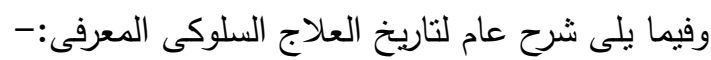
إن أهم مداخل العلاج المعرفى السلوكى هو ما يعرف بالعاجى بالعلاج العقلانى الانفعالى Rational Emotive Therapy (RET) الخمسينيات. وكان إليس Ellis قد وضع هذا المدخل كرد فعل لعدم إعجابه بطبيعة مدرسة

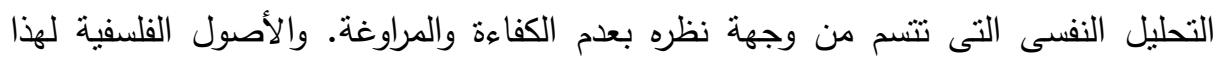

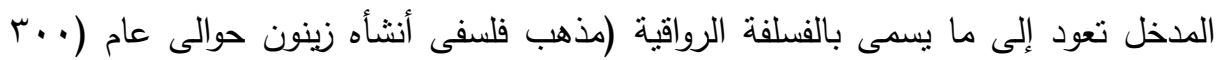
ق.م.) والذى قال بأن الرجل الحكيم يجب أن يتحرر من الانفعال ولا يتأثر بالفرح أو الترح وأن عالن

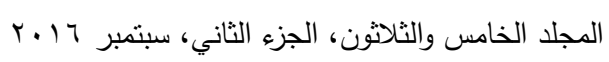


Epictetus يخع من غير تذمر لحكم الضرورة القاهرة) ومن أهم فلاسفته "إبيكتوتوس" و "ماركوس أوريليوس" Marcus Aurelius . ويقول "إبيكتوتوس" بأن الإنسان لا يصييه

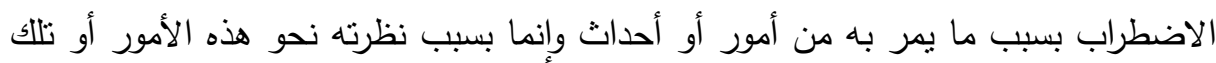

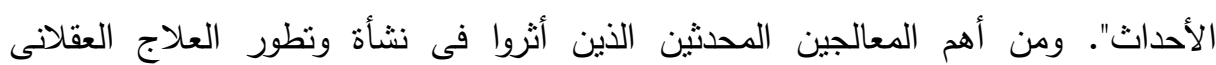

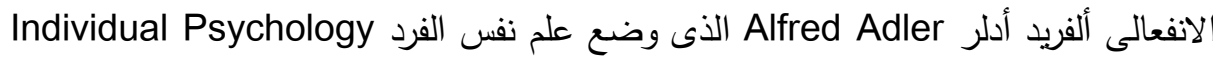
وهو من مدرسة فرويد الجديدة، حيث يقول: "أنا مقتتع بأن سلوك الفرد ينبع من أفكاره"، كذلك

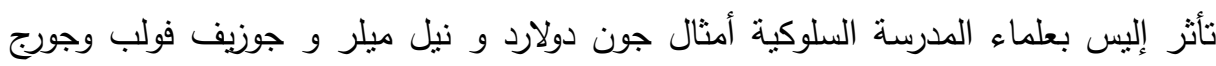
كيلى. وقد وضع إليس نموذجاً للتعامل مع الانفعالات عرف باسم ABC model ثم طوره بعد ذللك ليصبح مدخل ABCDE . وفى التسعينيات غير إليس اسم مدخله ليصبح باسم "علاج السلوك الانفعالى العقلانى". وفى الآونة الأخيرة تأثر العلاج المعرفي السلوكي بأحد أعمال ألدو بوتشى دكتور علم النفس بكتابه المسمى "علاج الحياة العقلانية" Rational Living Therapy ، وكذلك أعمال مايكل ماهونى ومارشا لينهان. وأرثر فريمان. (National Association of Cognitive-Behavioral Therapists. 2008) إن الربط بين عناصر المداخل المعرفية والسلوكية نجده من خلال مبدأ "التعزيز الذاتى".

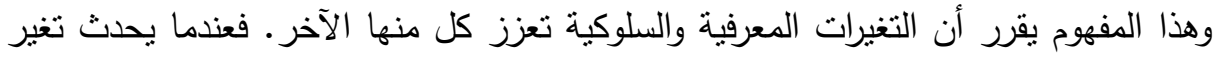

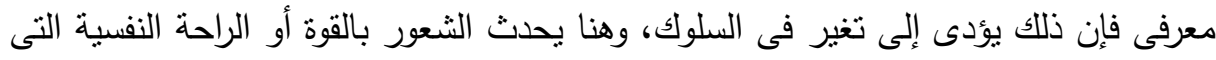
تدعم التغيير فى الفكر ومن ثم تدعم التغيرات فى السلوك. ويتولد عن ذلك تغذية مرتدة تعتبر

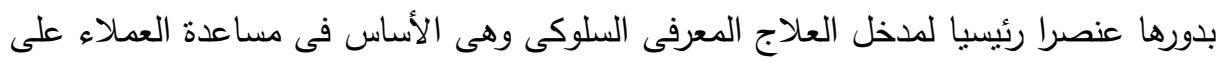
فهم العملية المعرفية السلوكية ودورتها فى عملية التغيير (Harvey Milkman , 2007). وعلى ذلك فالعلاج المعرفى السلوكى وبطلق عليه Cognitive Behavioral theory وهو يقوم على مبدأ أساسي وهو أن معارف الفرد تلعب دوراً مهماً وأساسياً فى عملية

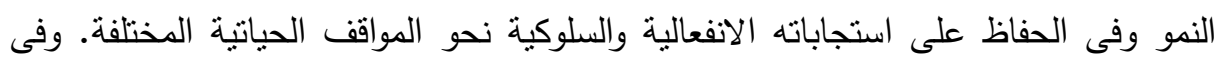
نماذج العلاج المعرفى السلوكى، تعد العمليات المعرفية، والنى تأخذ شكل المعانى والأحكام

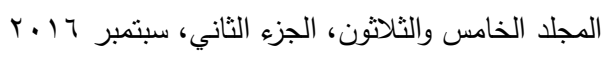


التى يصدرها الفرد وتقييماته وافتراضاته المرتبطة بأحداث حياتية معينة هى المحددات

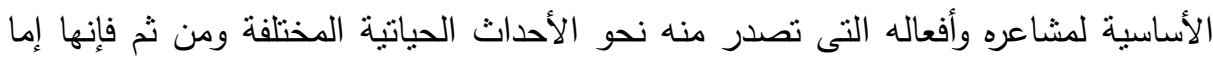
أنها تنهل عملية التوافق أو تعوقها. ويتضمن العلاج المعرفى السلوكى سلسلة من الدداخل التى ثبت فعاليتها فى علاج توترات مختلفة... وهناك ثلاثة افتراضات أساسية تكمن وراء النماذج المعرفية السلوكية الافتراض الأول: هو أن العمليات المعرفية والمحتوى المعرفى يمكن الوصول إليهما والتعرف

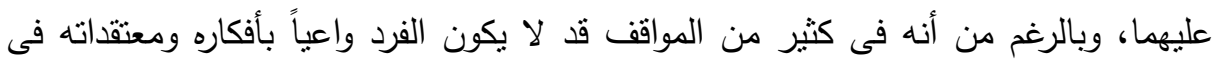

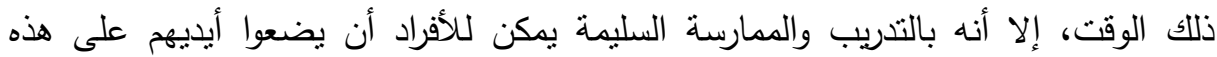

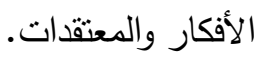
والافتراض الثانى: هو أن "التفكير" هو الوسيط الذى من خلاله نسلك طريقنا نحو استجاباتتا

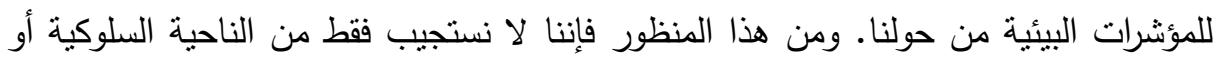
الانفعالية نحو الأحداث الحياتية، ولكن تؤمن النظرية المعرفية السلوكية أن الطريقة التى نفكر بها فى ما يحيط بنا من واقع هي مؤثر جوهرى وأساسى فى رد فعلنا نحو الأحداث المحيطة. والافتراض الثالث: هو أن مثل تلك المعارف يمكن استهدافها بشكل مقصود وتعديلها وتغييرها. وبالتالي فإنه عندما ينم تغيير مثل هذه المعارف عند توجهنا نحو تحقيق تفكير منوازن

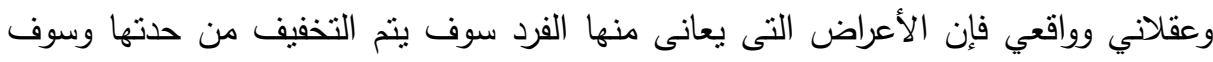

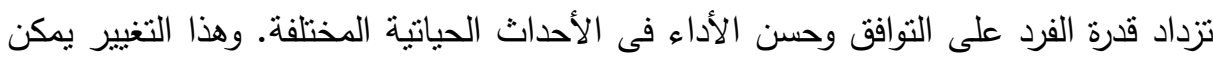

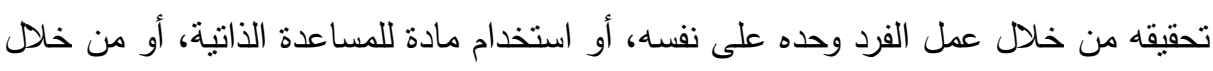

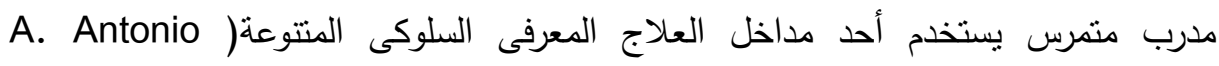
.(González , 2012

إن استخدام الباحثة هذا المدخل (المعرفى السلوكى) كموجه نظرى لها اتساقاً مع الها الفرضية الأساسية لهذا المدخل والتى فحواها أن تغيير السلوك السالب للفرد (السلوك غير الفئ

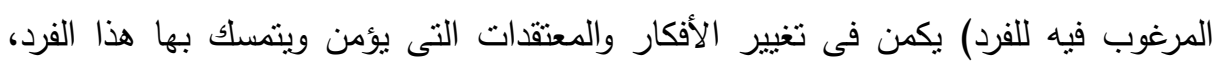
وتفترض الباحثة أن الإدمان والسلوك الإدمانى يمثل سلوك غير فئر مرغوب فيه (سلوك سالب)،

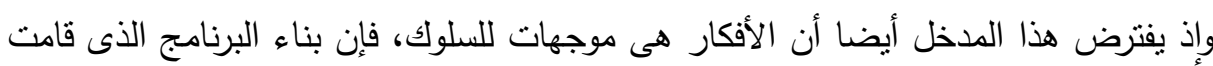

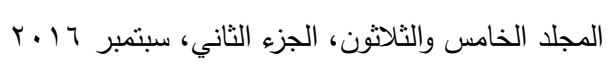


به الباحثة للحد من مشكلة الإدمان لدى انماط منباينة من الثخصية يعتمد على مد أو تزويد

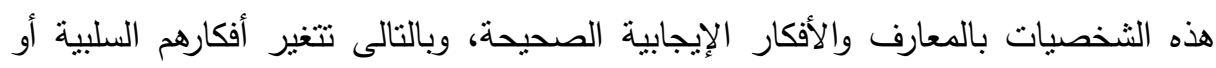

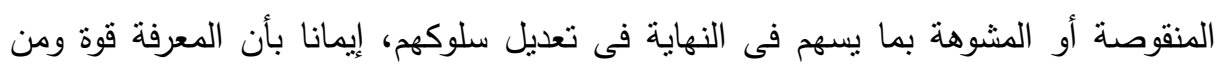
يمنلك المعرفة فهو يمنلك القدرة على التغيير الإيجابى.

\section{الاجراعات المنهجية للادراسة:}

المنهج المستخدم: استخدمت الباحثة المنهج العلمى باستخدام الأسلوب التجريبى. نوع الاراسة: نتتمى هذه الدراسة إلى نمط الدراسات التجريبية.

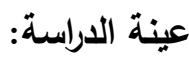

- تكونت عينة الدراسة من (1 ا ) من المنقطعين عن المخدر (سواء كان هيروين أو ترامادول أو حشيش) ويخضعون للبرنامج العلاجى، والعلاج الدوائى.

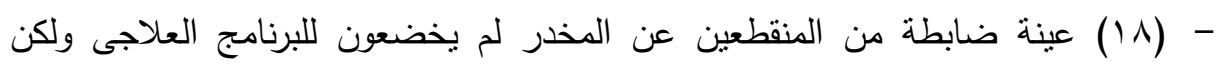
يتلقون علاج دوائى فقط.

- العينة من المركز الطبى النفسى للإدمان بجامعة عين شمس، حيث تعمل الباحثة بعيادات الإدمان والمتعافين من خلال صندوق مكافحة وعلاج الإدمان. الأدوات:

ا ـ مقياس التعديل المعرفى السلوكى للمنقطعين عن المخدر • (إعداد الباحثة)

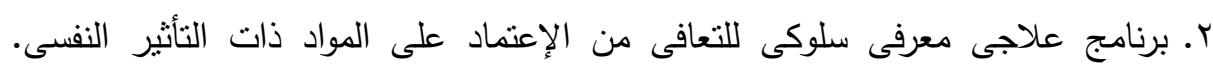
(إعداد الباحثة) وفيما يلى وصف لأدوات الدراسة بالتقصيل:-

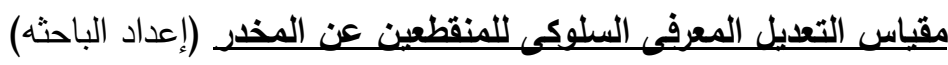

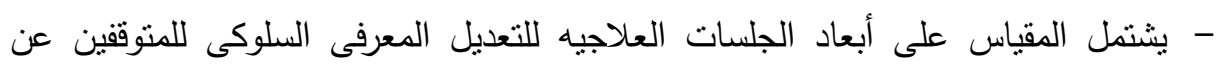
المخدر . - ويتضمن المقياس (• ـ) عباره تتضمن أهداف الجلسات العلاجيه. 
- وتم تحديد شكل اسئلة المقياس على أبعاد الجلسات العلاجية للتعديل المعرفى السلوكى

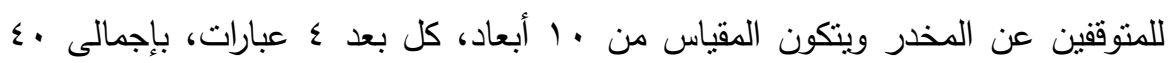

$$
\text { عبارة. }
$$

- وتم تحديد شكل اسئلة المقياس من نوع الأسئلة المحددة أو المقيدة، حيث يقوم المدمن باختيار الأستجابة بأحد المتغيرات المحددة التالية:

$$
\begin{aligned}
& \text { درجة واحدة } \\
& \text { 1- موافق بشدة } \\
& \text { درجتين } \\
& \text { r- موافق } \\
& \text { ثلاث درجات } \\
& \text { r- موافق أحيانا } \\
& \text { أربع درجات } \\
& \text { ـ - لا أوافق }
\end{aligned}
$$

وتدل الدرجة المرتفعة إلى زيادة فاعلية الجلسات العلاجية من خلال التعديل المعرفى لرجى

\section{أما أبعاد المقياس فكانت كالتالى:}

- البعد الأول: قياس مدى ثقافة المريض العلاجية (من خلال التعرف على طبيعه المرض

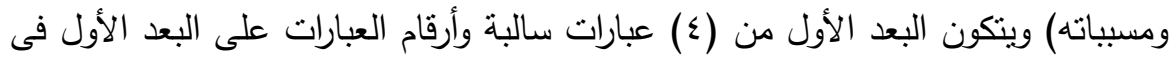

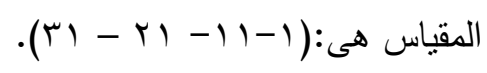

- البعد الثانى: قياس مدى الثقبل (تقبل المريض لطبيعة المرض).

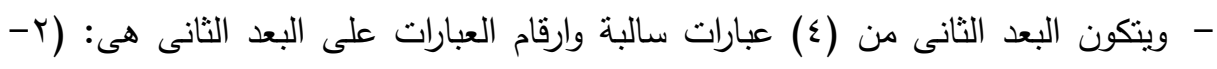

$$
\text { . }
$$

- البعد الثالث: قياس مدى تمسكه بالسلوكيات الإدمانية. (كالكذب - السرقة - النصب الحوارات ) ويتكون البعد الثالث من (ع) عبارات سالبة وأرقام العبارات على البعد الثالث

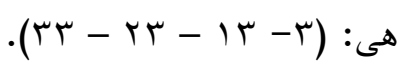

- البعد الرابع: تدريب الأسترخاء (للتعرف على كيفية التعامل مع التوترات الجسدية والنفسية

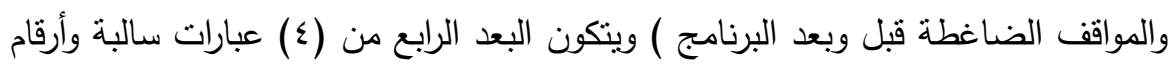

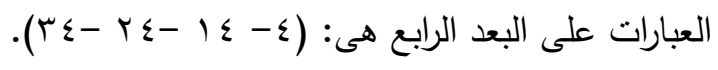

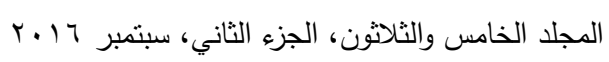


- البعد الخامس: بعد المعتقدات الخاطئة ( كالحشيش ليس إدماناً، أو ان علاج الإدمان مستحيل، أو ان المخدرات تعطى القوة وتساعد فى المواجهه وتحسن الأداء الجنسى)

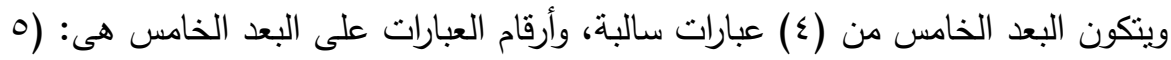
. ro- ro- $10-$ - البعد السادس: قياس كيفية التعامل مع اللهفة (مثثرات الفكر). ويتكون البعد السادس من

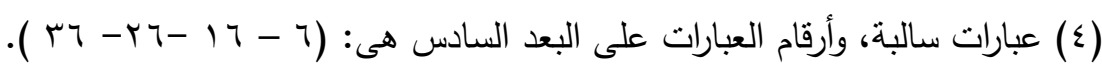

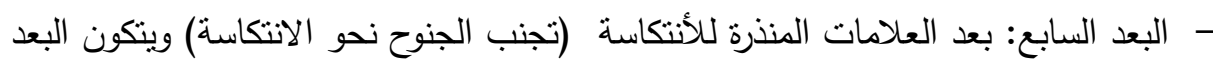

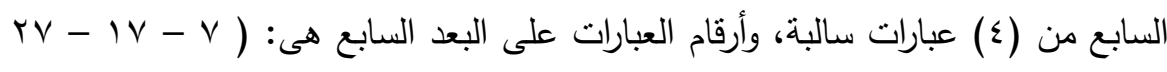
$. r V-$

- البعد الثامن: بعد تتمية الدافعية ( وذلك للتعرف على مدى دافعية المدمن المتوقف للتغيير

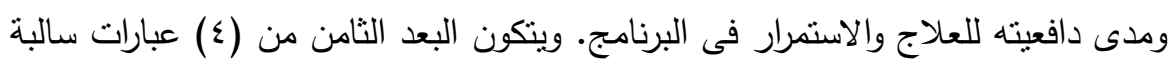
وأرقام العبارات على البعد الثامن هى: ( - البعد التاسع: بعد تعديل السلوكيات الإدمانية (من خلال التفكير العقلانى ورصد الأفكار

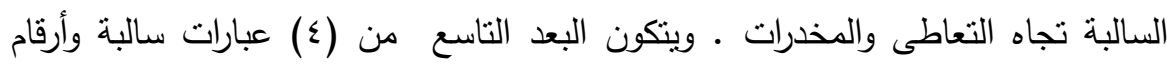

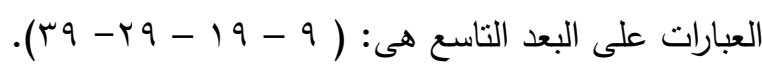
- البعد العاثر: قياس المهارات الثخصية (التواصل - حل المشكلات - مواجهه المواقف الضاغطة - التحكم فى الغضب) ويتكون البعد العانر من (ع) عبارات سالبة، وأرقام

$$
\text { العبارات هى:( • (- •r - • - - • ع). }
$$

البرنامج العلاجحي المعوفى السلوكى للتعافى من الإعتماد على المواد ذات التأثير النفسى

المكونات الأساسية للبرنامج العلاجى المعرفى:-

$$
\begin{aligned}
& \text { 1. تقديم معلومات حول الجلسة (الإدمان - الانتكاسة - التقبل ... الخ). } \\
& \text { r. تعليم المهارات لتسليحهم من الوقوع فى الإدمان مرة آخرى. } \\
& \text { r. وضع بعض المهام السلوكية (كالواجب المنزلى). }
\end{aligned}
$$


عدد الجلسات ومعدلها: يتكون البرنامج من (اثنى عشر) جلسة بواقع جلسة فى الاسبوع، مدة كل جلسة (ساعة ونصف).

المدى الزمنى للبرنامج: ينراوح المدى الزمنى للبرنامج اثثى عشر أسبوع أى (ثلاثة أشهر) .

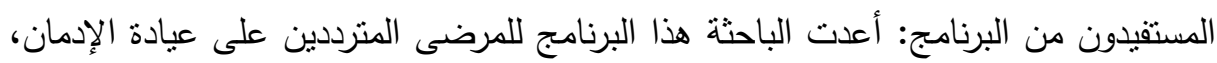
والذين نوقفوا عن التعاطى لددة ثلاثه شهور والتحقوا بالبرنامج العلاجى. الفنيات المستخدمة فى البرنامج: بعتمد البرنامج العلاجى على مجموعة من الأساليب والفنيات التى نم انتقائها ودمجها بشكل كامل لخدمة اهداف البرنامج وهى (المناقثات الجماعية -

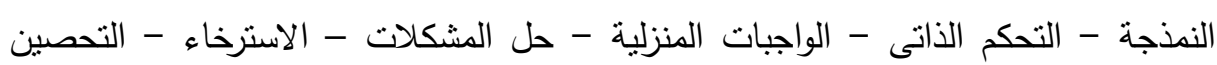
ضد الضغوط - التعزيز طريقة تقييم البرنامج - عرض البرنامج على المحكمين). الشبات والصدق للمقياس: (مقياس التعديل المعرفى السلوكى للمتوقفين عن المخدرات)

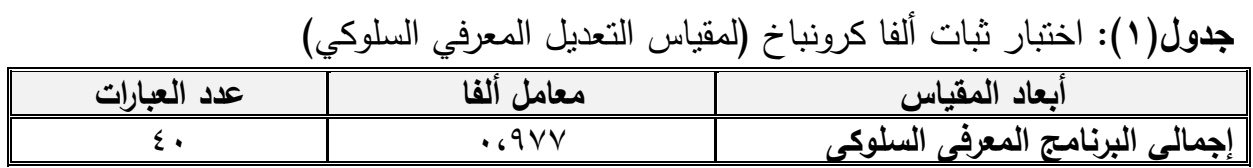

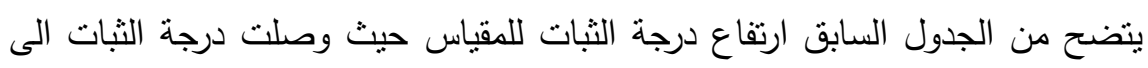
9VV فى التطبيق. جدول (Y): ثبات المقياس المعرفي السلوكي باستخدام التجزئة النصفية

\begin{tabular}{|c|c|c|c|}
\hline معامل الإرتباط المصحح & العبارات الزوجية & & أبعاد المقياس \\
\hline \multirow{2}{*}{$.69 \mathrm{~V}$} & $\left({ }^{(* 0)} \cdot 69 \leq 7\right.$ & معامل الارنباط & \multirow{2}{*}{ العبارات الفربية } \\
\hline &.$\ldots 1$ & الدلالة المعنوية & \\
\hline
\end{tabular}

يتضح من الجدول السابق أن قيم معامل الإرتباط دالة إحصائباً، حيث بلغت الدية لالة

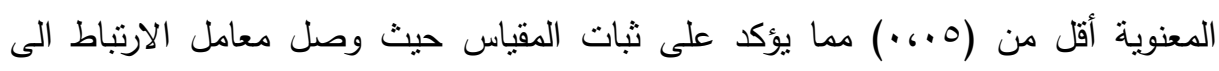

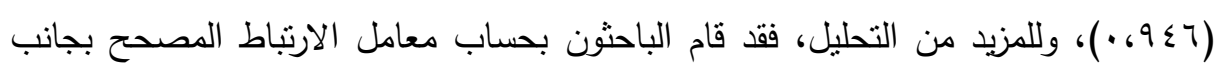

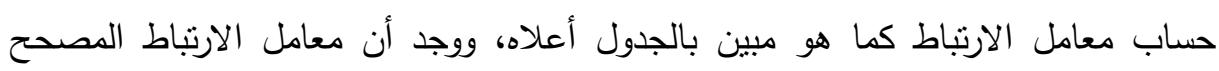
(9V ، • ) وهى قيم تؤكد على ثنات المقياس وتجعل الإعنماد عليه مؤكدا .

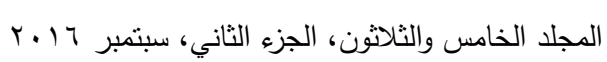


حساب الصدق للمقياس: قام الباحثون بعمل الصدق الظاهرى للمقياس الأداة الرئيسية التى

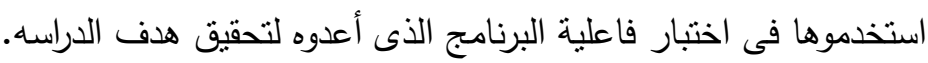
إجراءات الاراسة: اتبع الباحثون مجموعه من الخطوات لإتمام الجانبين النظرى والميدانى للاراسة على النحو التالى: - عمل بحث شامل ومتكامل عن أهم الدراسات والبحوث السابقة ذات الصلة بموضوع الدراسة الراهنة سواء كانت هذه الدراسات باللغه العربية أو اللغة الإنجليزية.

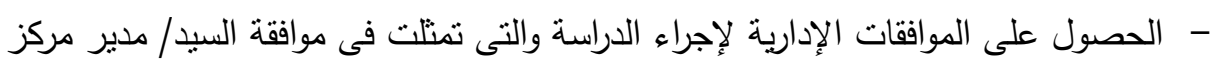
الطب النفسى بمستشفى الدمرداش بالقاهرة. - - اختيار المجال البشرى للاراسة. - تطبيق البرنامج ومقياس الدراسة على المرضى المتوققين عن الإدمان فى المركز الطبى

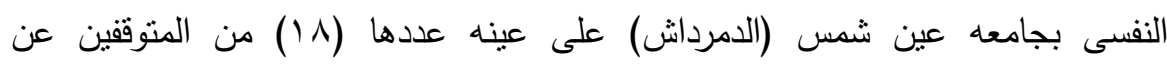
المخدر .

- تطبيق المقياس القبلى على المدمنين المتوقفين وهو مقياس التعديل المعرفى السلوكى للمدمنين المتوقفين. - تطبيق البرنامج العلاجى المعرفى السلوكى للمدمنين المتوققين بواقع جلسة كل أسبوع، لمدة (نثلاثة أنثهر ). - بعد انتهاء البرنامج العلاجى المعرفى السلوكى، قام الباحثون بتطبيق بطارية المقاييس مرة

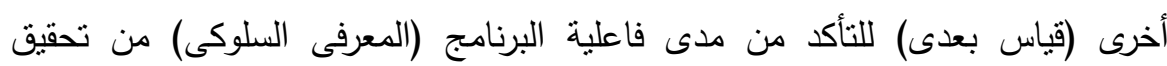
الأهداف المرجوة منه. المعالجة الإحصائية: المأه • استخدم الباحثون اختبار ( T.Test) وهو من أهم الاختبارات الإحصائية النى تستخدم لمعرفة الفروق بين المجموعات المحكمة، التى يقل عددها عن ( • م ) مفردة.

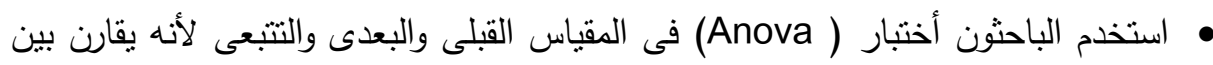
أكثر من عينتين. 
قد اعتمد الباحثون فى استخراج البيانات الإحصائية سواء البسيطة أو المركبة على

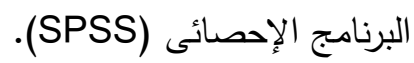

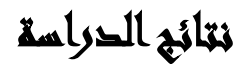

يوجد فروق ذات دلالة إحصائية نتيجة تطبيق برنامج معرفى سلوكى على عينة من المدمنين المتوققين قبل تطبيق البرنامج وأثناء النطبيق وبعد التطبيق. ويقصد فى هذا الفرض أن وجود فروق ذات دلالة إحصائية على مقياس التعديل السلوكى المعرفى للمدمن المتوقف. ويقيس مقياس التعديل المعرفى السلوكى للمدمن المنوقف، مجموعه أبعاد ويتضمن كل

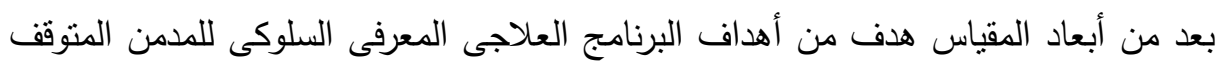
على النحو النالى: - الى 1 بعد ثقافة المريض العلاجية. r. بعد تقبل المريض لطبيعه المرض.

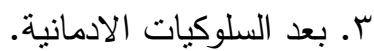
ع. بعد التدريب على الاسترخاء.

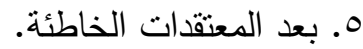
7. بعد مواجها التعامل مع اللهفة.

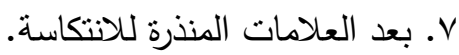

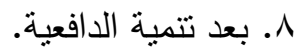
9 9. بعد تعديل السلوكيات الإدمانية.

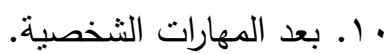

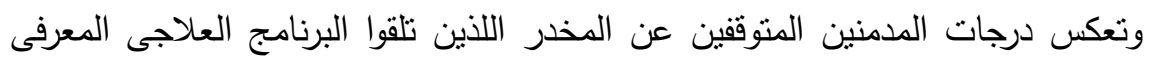
السلوكى، مدى الثقافة العلاجية المكتسبة من البرنامج وزيادة تقبل المريض لمرض الادنين الادمان حتى يستطيع اكمال البرنامج العلاجى بنجاح ومدى تمكنهم للتعامل مع اللهفة، وتصحيح 
المعتقدات الخاطئة واكتساب مهارات كمهارة التواصل وحل المثكلة والتدريب على الاساليب

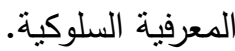

بينما تشير درجات المجموعة الضابطة (الذين لم يتلقوا البرنامج) عدم تمكنهم من امتلاك المهارات والاساليب المعرفية السلوكية فى مجابهة مرض الادمان.

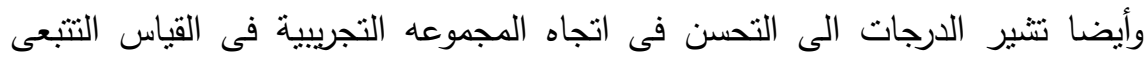
للبرنامج من خلال الاجابة على مقياس التعديل المعرفى السلوكى للمدمن المتوقف عن

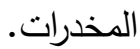

وتتير هذه المعانى إلى صدق الدفحوصين فى الاستجابة على مقياس التعديل المعرفي السلوكى للمدمن المنوقف عن المخدرات، والتعبير عن تمكنهم من المهارات والأساليب

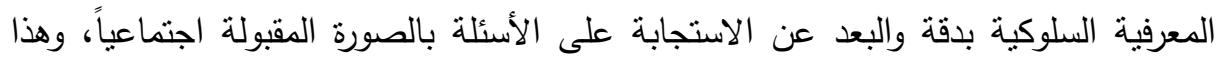
يتضح من خلال إجابات المفحوصين على المقياس من خلال القياس القبلي للمجموعة الضابطة والتجريبية ومقارنته بالقياس البعدى للمجموعة الضابطة والتجريبية مما يظهر فروق ذات دلالة إحصائية فى اتجاه المجموعة التجريبية التى تلقت البرنامج العلاجى المعرفى السلوكى وتدربت وأتقتت المهارات والأساليب المعرفية السلوكية المتضمنة فى البرنامج

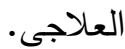
ويمكن تفسير ما توصلت إليه الدراسة الحالية من خلال الاتفاق مع نتيجة (لورانس وآخرون . . . أن أن البرنامج العلاجى المعرفى السلوكى من خلال التدريب على المهارات داخل البرنامج ينتج عنه التأقلم والتغلب على الضغط الاجتماعى والعزلة والوحدة المنزلية والشعور بالأكتئاب والقلق والتوتر والغضب والاحباط. وأسفرت الدراسة عن استجابات المدمنين المنتكسين بشدة الكرب النفسى المرضى وأنهم بعد البرنامج العلاجى كانت معدلاتهم أكثر ارتفاعاً بهؤلاء الذين لم يكملوا البرنامج وتؤكد المدين الدراسة أن الطرق المعرفية تعمل بشكل جيد مع الكبار المنخرطين فى المشكلات الطبية والاجتماعية واستعمال المخدر ذو دلالة. 
ويتضح فى الدراسة الحالية ارتفاع درجات المجموعة التجريبية عن المجموعة الضابطة فى التغلب على الضغط ومهارة التحصين ضد الضغوط وحل المشكلات ورصد أساليب التفكير الخاطىء (التشوه المعرفى) وتعديل السلوكيات بالمقارنه بالمجموعة الضابطة التى لم وهيل تتلقى تدريب على المهارات والأساليب المعرفية السلوكية.

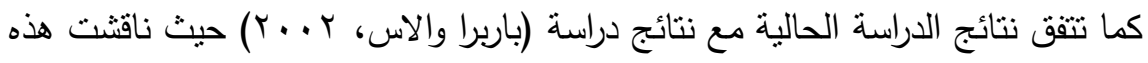
الدراسة البرامج العلاجية طويلة المدى للوحدات الداخلية، والتى تعد من أقدم الأساليب المتبعة فى علاج مشاكل إدمان المخدرات لدى المتعاطين. وقد هدفت هذه الدراسة إلى الكثف عن مدى فاعلية هذه البرامج فى علاج مشاكل الإدمان، ومنهم جمهور المدمنين الأكثر ملائمة لتلقى مثل هذه النوعية من العلاج.

ومن خلال درجات المجموعة التجريبية على مقياس التعديل المعرفى السلوكى نجد ان البرنامج المعرفى السلوكى للمدمن المتوقف ركز على أهمية الاسترخاء والتحصين ضد الضغوط ومواجهه المواقف الضاغطة واتضحت درجات الهجوعة التجريبية على التدريب على (الاسترخاء والتحصين ضد الضغوط ومواجهة المواقف الضاغطة) من خلال نتائج المقياس مقارنة بنتائج المجموعة الضابطة.

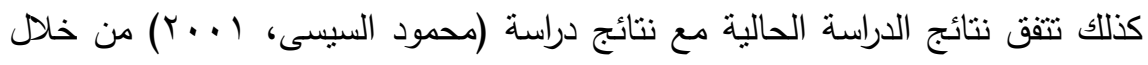
تأكيدها على فعالية العلاج المعرفى السلوكى وتعديل السلوك البيئى، حيث أسفرت نتائج الدراسة على اهمية العلاج المعرفى السلوكى على مقياس السلوك البيئى مما يؤكد فعالية المدخل العلاجى المتمثل فى المدخل المعرفى السلوكى فى تحسين حالة المدمنين. 
وهذا ما اتبعته الدراسة الحالية من خلال استخدمها المدخل المعرفى السلوكى لتعديل السلوكيات الإدمانية واحلال سلوكيات حميده بدلا من سلوكيات الإدمان كالصدق والاعتتاء

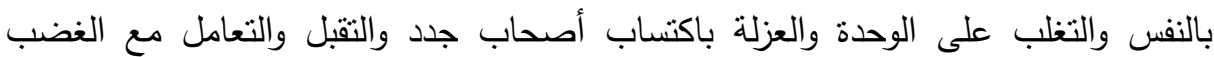
وإصلاح العلاقات.

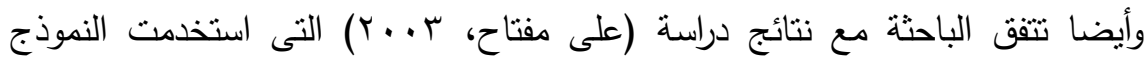

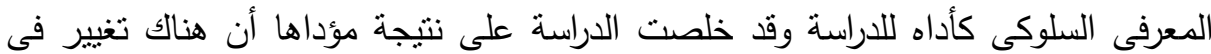

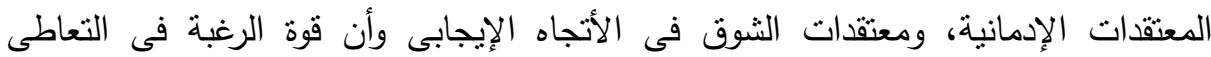
واحتمالية التعاطى قد ضعفت نتيجة التذخل. وهذا يؤكد ان الطرق المعرفية السلوكية تعمل بشكل أمثل مع مرضى الإدمان فى كلتا الدراستين.

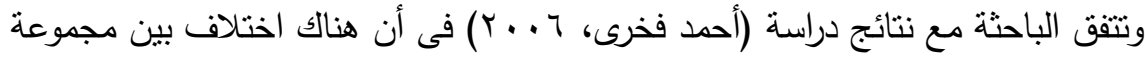
الدمنين المنتكسين الذين تلقوا البرنامج العلاجى المعرفى السلوكى، ومجموعة المدمنين المنتكسين الذين لم ينلقوا البرنامج العلاجى، وأظهرت النتائج أن المدمنين المنتكسين الذين تلقوا البرنامج العلاجى أصبح لديهم وعى وإدرالك بالعلامات، والمؤشرات التحذيرية المنذرة لفين بالانتكاس من علامات معرفية، وانفعالية وسلوكية وأن الانتكاس ليس مجرد الاستخدام مرة

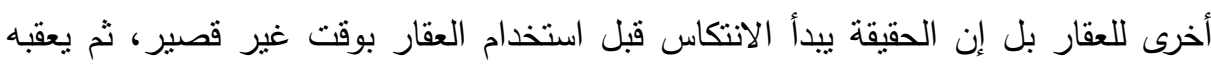
استخدام للعقار لمدة طويلة ومستمرة. كما أظهرت النتائج الخاصة بالمدمنين المنتكسين الذين تلقوا البرنامج العلاجى المعرفى السلوكى تمكنهم من استخدام المهارات والأساليب المعرفية السلوكية المتضمنة فى البرنامج العلاجى من تتمية للافعية للعلاج من الإدمان وتحسن دافعيتهم للعلاج والخلاص من براثن

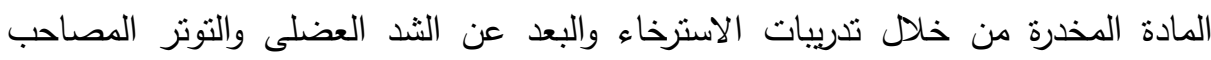
للددمن، وخاصة عند الثعور بالاثتهاء للمخدر، وكذلك مراقبة الذات والأحاديث السلبية المرنبطة بدفع المدمن إلى العودة للتعاطى مرة أخرى وتمكنه من إعادة تشكيل بنية الحديث

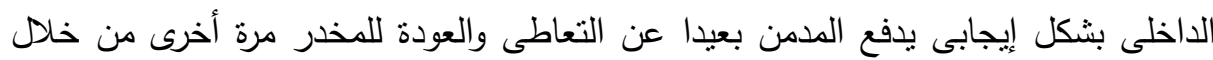

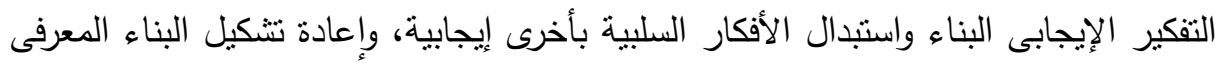

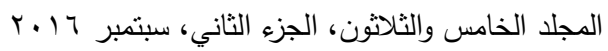


من خلال التعرف على التشوهات المعرفية التى تؤدى على اضطرابات انفعالية وسلوكيات

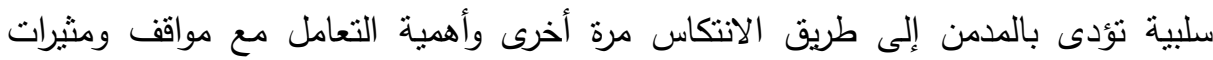
الانتكاس والأفكار المرتبطة بالاتكاس باستخدام المهارات والأساليب الإلهائية السلوكية، والمعرفية، وتمكن المدمنين من توكيد ذاتهم من خلد المواجهة والتفكير المنطقى فى حل بل بله المشكلات ومواجنها والتعبير عن المشاعر بأسلوب منطقى، وأهمية الرفض للطلبات غير هن

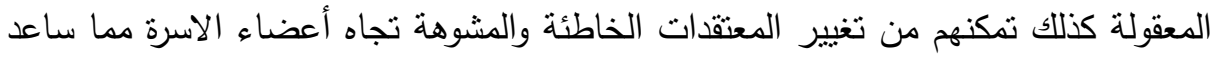
على تحسين المناخ البيئى الأسرى من الصراعات والاضطرابات الانفعالية وقد أظهرت النتائج أيضا أن أسر المدمنين المنتكسين الذين تلقوا البرنامج الإرشادى قد اتسمت بيئته المنزلية بالتوافق فى تواصلهم بعضهم مع بعض، وتمكنوا من استخدام الأساليب والمهارات المعرفية الهنية السلوكية أثناء تدريبهم وإعادة البناء المعرفى لديهم فى مواجهتهم للمشكلات والتفاوض فيما بينهم وأصبح لديهم وعى وإدراك، كما تحسن لديهم الجانب المعرفى السلوكى. ثورئ. وهذا ما أكدت عليه الدراسة الحالية من خلال درجات المجموعة التجريبية على مقياس

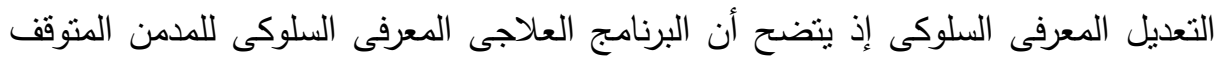

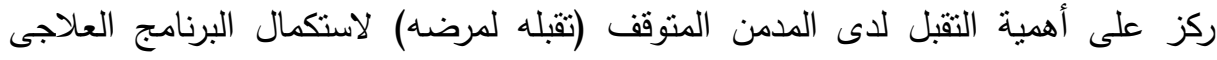
بنجاح، وأيضا مواجهة المواقف الضاغطة والتحصين ضد الضغوط، والتنفيس الانفعالى، وأكدت الدراسة على أهمية الاسترخاء لصفاء الذهن والتواصل الجيد، وتصحيح المعتقدات الخاطئة، وتقوية إرادة المدمنين المتوقفين فى اعتناق معتقدات بديلة صائبة، وحقق البرنامج البناه أيضا فعالية فى تجنب الجنوح نحو الانتكاسة، وكانت أيضا المجموعة التجريبية لديها دافعية الفية أكبر من المجموعة الضابطة من خلال التدريب على التأمل والتحكم فى الذات، وقد نم تعديل السلوكيات الإدمانية لدى المجموعة التجريبية بشكل واضح أكثر من المجموعة الضابطة مما جعلهم يكتسبوا العديد من المهارات الثخصية والاجتماعية للاستمرار فى التعافى.

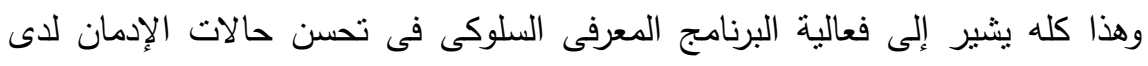
المجموعة التجريبية مقارنة بالمجموعة الضابطة التى لم تخضع للبرنامج الذى صممته 
وقد راعت الباحثة خلال مرحلة تصميم البرنامج العلاجى المعرفى السلوكى للمدمنين المتوقفين عن المخدرات التركيز على أن تكون المرحلة الأولى من البرنامج تعليمية، بينما

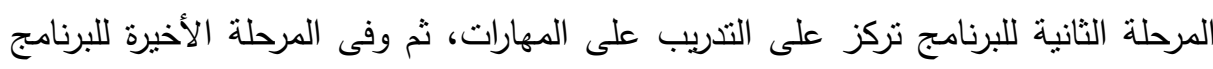

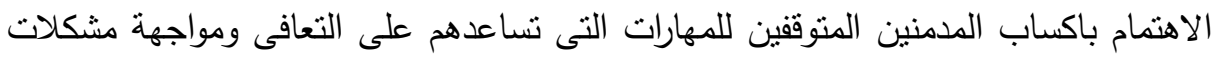

حيث ركزت الباحثة فى المرحلة الأولى للبرنامج على إمداد المدمنين المتوقفين بالمعلومات والمعارف المتعلقة بطبيعة مرض الإدمان وخطورته على الفرد والأسرة، وتوضيح أن المدمن مريض وليس مجرم، والتعرف على مثيرات الفكر والعوامل المثيرة لللهفة والأفكار المرتبطة بالتعاطى، ومحاولة الوصول إلى درجة عالية من التقبل. بينما ركزت المرحلة الثانية على مهارة الاسترخاء للتنفيس الانفعالى والتواصل الجيد وللتخلص من مثيرات الغضب والتوتر، ثم بدأت الباحثة فى توضيح السلوكيات الإدمانية وكونها مرنبطة فقط بالإدمان أو عند الجنوح نحو التعاطى. وفى المرحلة الثالثة حاولت الباحثة تصحيح المعتقدات الخاطئة واستبدالها بأفكار عقلانية، والتذريب على رصد العلامات المنذرة بالانتكاسه، وتتمية الدافعية من خلال التحكم فى الذات ثم تعديل السلوكيات لمواصلة طريق التعافى، ثم اكتساب العديد من المهارات الثخصية منل التواصل وإدارة الغضب، وحل المشكلات، والتغلب على السلبية. وقد اتضحت فعالية البرنامج من خلال ارتفاع درجات المجموعة التجريبية على المقياس بعد تطبيق البرنامج. وتتقق النتائج والتفسيرات السابقة دع نظرية التعديل السلوكى المعرفى لرائدها دونالد هربرت ميتشنبوم الذى بنى نظريته على مزج بعض المفاهيم السلوكية مع بعض المفاهيم

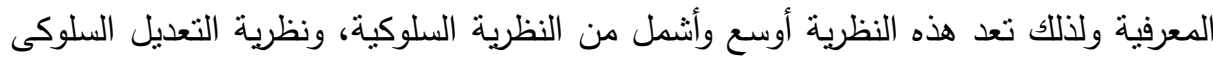

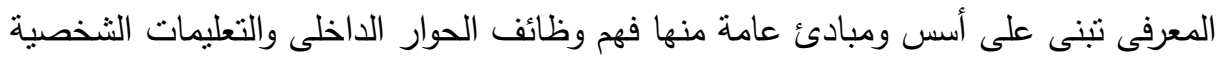

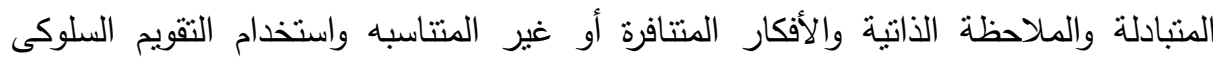
المعرفى وإعادة البنية المعرفية والتدريبات على حل المشكلات وتعلم مهارات المواجهة والتأقلم

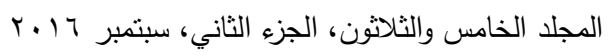


وضبط الذات وأساليبه مع التركز على هدف اكتساب التعلم وإحداث التغير فى السلوك وفى

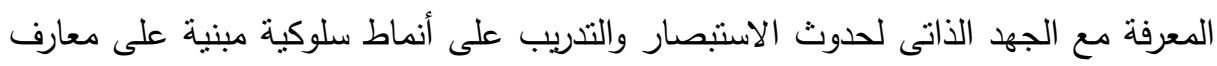
عقلانية تفيد فى التأقلم (مدحت أبو زيد، 1 . . ب).

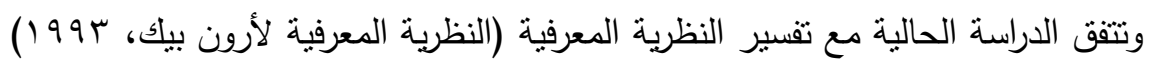

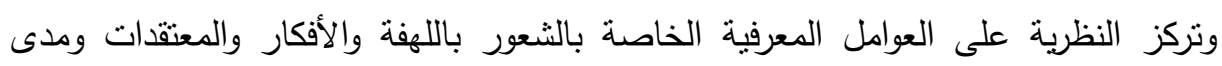
التفاعل القائم بينهما والتفاعل بين المعتقدات يكون على النحو التالى: اعتقاد رئيسى بنطور

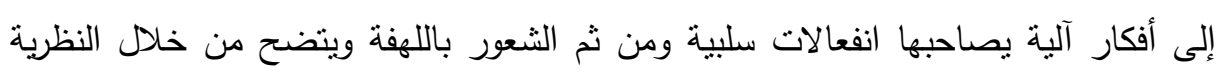
المعرفية أن المعتقدات تؤثز بعضها على البعض الآخر فى تفاعل ويمتد هذه التأثير ليشمل

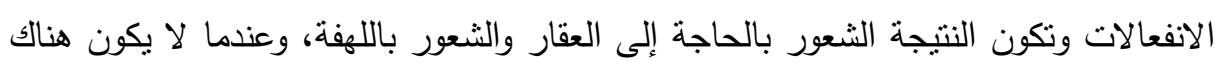

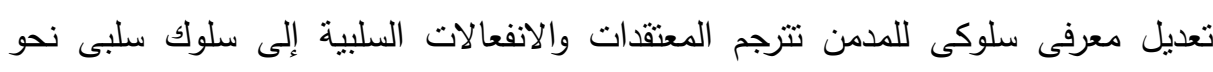
التعاطى، ومن ثمة الانتكاسة.

ويتضح من خلال درجات المجموعة التجريبية (قياس بعدى) على مقياس التعديل

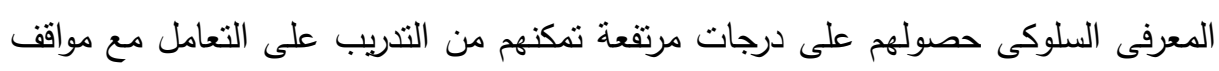
ومثيرات الانتكاسه والتدريب على التفكير العقلانى وتحدث الأفكار غير المنطقية وتثقييمها وتعديلها. وبهذا يتحقق صحة الذى مؤداه توجد فروق ذات دلالة إحصائية نتيجة نطبيق برنامج

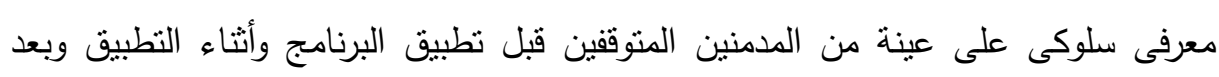
التطبيق فى اتجاه المجموعة التجريبية. وبالتالى فإن النتيجة النهائية لهذه الدراسه مؤداها: فعالية مثل هذه النوعية من البرامج فى النى

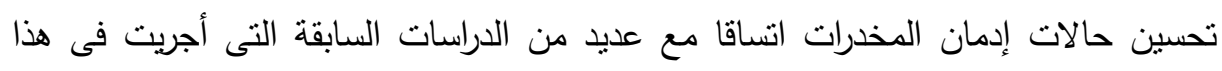
الصدد. 
مجلة العلوم البيئية

معهد الدراسات والبحوث البيئية - جامعة عين شمس له

\section{توصياهت الدواسمة}

• إجراء المزيد من الدراسات التجريبية التى تتتاول فئات مختلفة من الثخصية وفى بيئات منباينة.

دعوة كافة المهن والتخصصات للتضافر لمواجهة هذه المظاهرة فى كافة البيئات

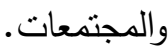

الدعوة إلى تتسيق الجهود وتبادل المعلومات بين المؤسسات الدولية والمحلية فيما يخص

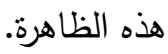

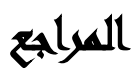

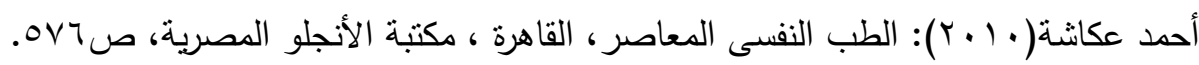

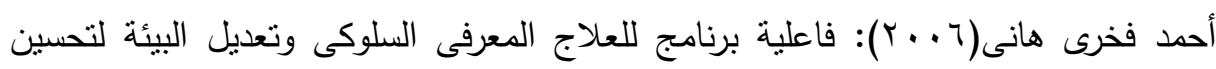

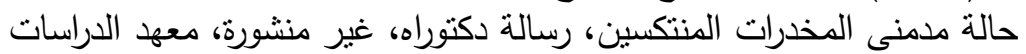

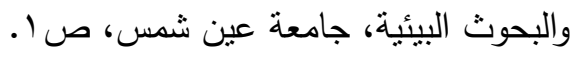

أشرف على عبده:( . . †): سيكرلوجية الادمان من منظور علاجى حديث، القاهرة: المركز

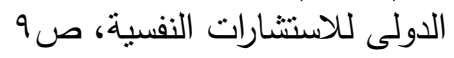

التقرير العالمى للمخدرات(§ ( †): الصادر عن مكتب الأمم المتحدة المعنى بالمخدرات والجريمة

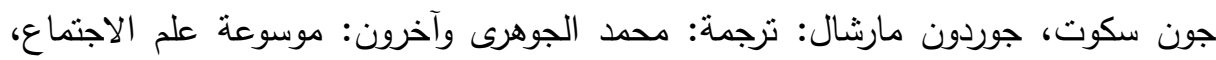

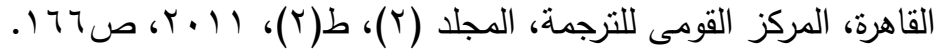

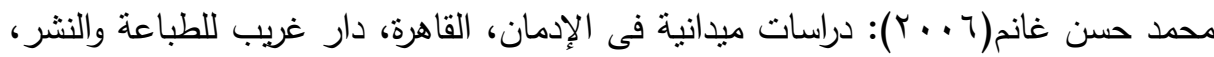

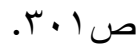

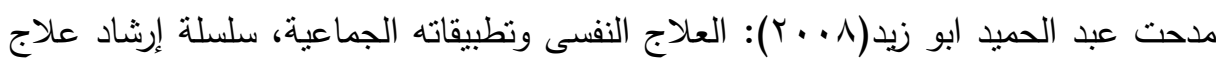

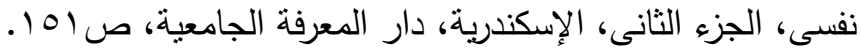
المسح القومى الثنامل(1) (1 ب): صندوق ومكافحة وعلاج الإدمان والتعاطي 
أحمد مصطفى العتيق وآخرون

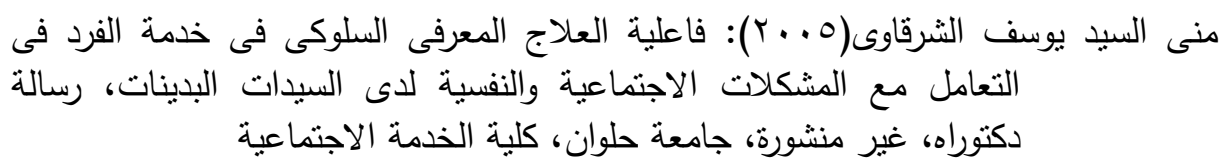

A. Antonio González-Prendes and Stella M. Resko (2012): CognitiveBehavioral Theory, in Shoshana Ringel \& Jerrold Brandell (editors): Trauma; Contemporary Directions in Theory, Practice, and Research. SAGE Publications, Inc., pp. 14-15.

Harvey Milkman; Kenneth Wanberg (2007): "Cognitive Behavioral Treatment: A Review and Discussion for Corrections Professionals" .S. Department of Justice National Institute of Corrections, Washington, DC., pp.7-9.

Kristen Lawton Barry: Brief Interventions And Brief Therapies for Substance Abuse. US Department of Health and Human Services, Public Health Service, 1999.

Lisa Miller: Counseling Skills for Social Work, SAGE Publication, London, 2006, p.57.

National Association of Cognitive-Behavioral Therapists. 2008.

http://nacbt.org/historyofcbt.html

$$
\text { المجلد الخامس والثلاثون، الجزء الثاني، سبتمبر } 1 \text { ا بـ }
$$




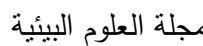

معهد الدراسات والبحوث البيئية - جامعة عين شمس لمس لمس

\title{
EFFECTIVENESS OF COGNITIVE THERAPY AND ENVIRONMENTAL TREATMENT OF IMPROVEMENT IN CASES OF DRUGS ADDICTION
}

El-Atik, A. M. ${ }^{(1)}$; Hany, A. F. ${ }^{(1)}$ and Abdel Fatah, Rania, H.

1) Institute of Environmental Studies \& Research, Ain Shams University

\begin{abstract}
This study drives at identifying the problem of drugs addiction and use in the past and at present. This critical problem represents a crucial obstacle in front of governments that seek achieving development and make the targeted urban transformation. Consequently, this problem is considered a global phenomenon that occupies a great concern from organizations, authorities, and institutions that are established for the purpose of combating this phenomenon all over the world states. This problem is also considered and studied by media and decision-makers in all societies and countries. Since youth are the basic pillar of any state that create societies' progress, it is noticed that several classes in Egyptian society are involved in addiction including Egyptian youth who try different kinds of drugs who has motivated researchers to examine the effectiveness of the cognitive behavioral therapy to improve drug addiction cases since addiction is irregular behavioral pattern.

The researchers used the scientific method using a quasiexperimental style, and the study tools consisting of a treatment program of cognitive behavioral and scale adjustable CBT to cut off from the drug, the study sample consisted of 18 (the same experimental) from the drop-drug undergoing drug treatment and treatment program together, and also 18 (sample set) from the drop-
\end{abstract}

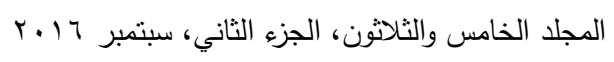


drug undergoing drug treatment only, the application was in the psychological Medical Center on addiction at Ain Shams University and was the number of sessions 12 sessions by sitting every week and the duration of the session and a half hours and was the total duration of the program for three months.

Most important search results are: no statistically significant differences as a result of the application of cognitive behavioral program on a sample of addicts Almtoagafin before and after the application of the program for the benefit of a sample program. 